\title{
Physiological left ventricular hypertrophy
}

\author{
L M SHAPIRO
}

From the Cardiac Department, Brompton Hospital, London, and the Physical Education Department, University of Birmingham, Birmingham

SUMMARY Echocardiograms were recorded in 154 active athletes (from various sports) and 21 exathletes and compared with those in 40 normal control subjects (non-athletes). Diastolic cavity dimension and posterior wall and septal thickness were measured and left ventricular mass and the ratio of posterior wall thickness to cavity radius and of septum to posterior wall thickness calculated. As a group athletes had a significantly increased diastolic cavity dimension, posterior wall and septal thickness, and left ventricular mass. The ratio of posterior wall thickness to cavity radius was distributed as a single continuous variable with a significantly increased mean, and there was no separate subgroup of shot putters or weight lifters with inappropriate hypertrophy. The mean ratio of septum to posterior wall thickness was normal, but there was a wide range of values up to $2 \cdot 1: 1$. Ex-athletes had entirely normal left ventricular dimensions and wall thickness. When athletes are categorised by their standard of competition national standard competitors had a significantly increased posterior wall and septal thickness and left ventricular mass compared with university and non-competitive sportsmen.

In conclusion, strenuous activity results in left ventricular hypertrophy which is appropriate to the body size of the athlete and the degree of activity but not to its type.

The heart has been studied in sportsmen since the development of modern athletics, and whereas there is no doubt that the left ventricle responds to prolonged strenuous activity by hypertrophy there remains considerable controversy about its form. ${ }^{1-18}$ The purpose of this present study was to consider the relation of various types of exercise training and left ventricular hypertrophy in a large number of active sportsmen and past athletes.

\section{Subjects and methods}

\section{ATHLETES}

Athletes were defined as individuals who pursued active endurance or power (not skill alone) training for at least three hours a week for one year and had achieved at least university competitive status. In addition, non-competitive sportsmen who performed a similar amount of exercise were studied. High quality echocardiograms were obtained in 157 athletes from a wide range of sporting disciplines and abilities, who were aged 18-59 years and included 91 men and

Requests for reprints to Dr L M Shapiro, National Heart Hospital, Westmoreland Street, London W1M 8BA.

Accepted for publication 15 May 1984
66 women. The major competitive sport in these subjects was swimming in 33 , running in 32 , throwing events in 15 , weight lifting in 19 , wrestling or judo in 16 , canoeing in 14 , and ball sports in 28 . Predominantly strength events were considered to be weight lifting, shot putting, and hammer and discus throwing. Endurance events included swimming, running, and canoeing. Many, however, participated in several sports which were a mixture of isometric and isotonic exercise. The best competitive standard achieved was recorded as international or national in 59 and university in 68; 30 were non-competitive sportsmen. Twenty one national standard athletes (ex-athletes) who had not trained for at least five years were also studied. In each subject the type and duration of exercise training were recorded, height and weight measured, and body surface area calculated.

\section{NON-ATHLETES}

Forty healthy non-athletic students (25 men, 15 women; age 18-27 (mean 21) years) underwent a similar echocardiographic study.

\section{ECHOCARDIOGRAPHY}

Recordings were made with an ATL mark III instrument using a $3.5 \mathrm{MHz}$ transducer. A complete cross 
sectional echocardiographic study was performed including parasternal long axis and short axis views of the left ventricle. The studies were recorded as real time images on 0.75 inch video tape using a Sony U-matic recorder (Type VO 2631). End diastolic stop frames were displayed using a video recorder with digital frame advance (Sony 5800 PS). From the recordings the following measurements were made directly with calipers at the level of the tips of the mitral valve (Fig. 1): (a) end diastolic posterior wall (PW) and septal thickness (VS) $(\mathrm{cm})$ at maximum cavity size and $(b)$ end diastolic left ventricular cavity dimension (DD) in $\mathrm{cm}$. These measurements were used in the following calculations: $(a)$ the ratio of wall thickness to cavity radius ( $T: R$ ) as $2 \mathrm{PW} / \mathrm{DD}$; (b) left ventricular mass (as all subjects had normal left ventricular shape and function the simplest equation (cube volume formula) was used to differentiate between the groups) as $([\mathrm{PW}+\mathrm{VS}+\mathrm{DD}] 3-\mathrm{DD} 3) \times 1.055$; and $(c)$ the ratio of ventricular septum to posterior wall thickness. Measurements of posterior wall, ven-

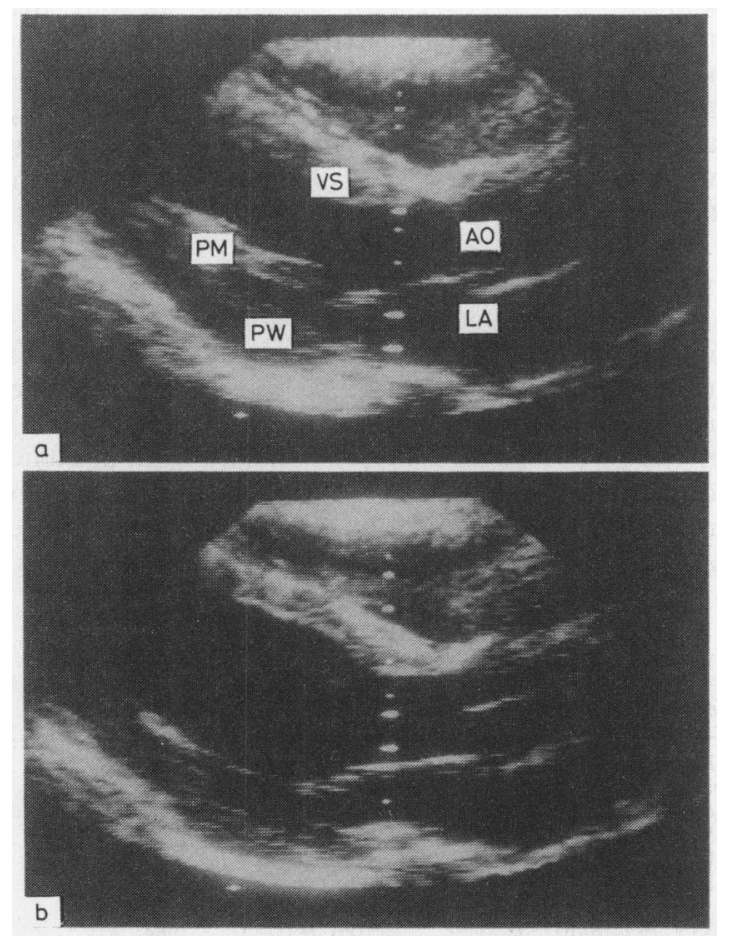

Fig. 1 Long axis cross sectional echocardiograms of (a) an endurance swimmer showing pronounced concentric hypertrophy with septum and posterior wall $1.5 \mathrm{~cm}$ thick. $P M$, papillary muscle; PW, posterior wall; VS, septum; $A O$, aorta; LA, left atrium: and $(b)$ an endurance runner showing cavity enlargement and moderate posterior wall and septal thickening. tricular septum, diastolic dimension, and mass were divided by the body surface area.

\section{STATISTICAL METHOD}

Values are expressed as mean (one standard deviation (SD)). Differences between measurements were determined by Student's $t$ test or the Mann-Whitney $\mathrm{U}$ test. The reproducibility of this method has been previously reported. ${ }^{19}$

\section{Results}

Two athletes had systolic clicks and murmurs and echocardiographic mitral valve prolapse, and one had a thick bicuspid aortic valve with left ventricular hypertrophy and dilatation suggesting significant aortic valve disease. These three were excluded, and 154 active athletes and 21 ex-athletes form the basis of the study.

\section{ATHLETES VS NON-ATHLETES}

Compared with non-athletes, the athletes showed increased posterior wall and septal thickness $(p<0.001)$ (Table 1, Fig. 1). Diastolic dimension was significantly increased $(p<0.001)$, and there was a wide range of values with $34>2 S D$ from normal. Left ventricular mass was increased $(p<0.001)$, and 50 athletes had a left ventricular mass $>157 \mathrm{~g} / \mathrm{m}^{2}(>2 S D$ from normal), of whom all but three performed endurance events (Fig. 1). There was a range of values for $T: R$ ratio $(0.27-0.57)$ with the mean greater than normal $(p<0 \cdot 01)$. Fig. 2 shows that the $T: R$ ratio is a single continuously distributed variable with no separate subgroup representing a group with inappropriate left ventricular hypertrophy. Forty eight athletes had a $T: R$ ratio $>2 S D$ from normal $(>0.43)$. The mean ratio of septum to posterior wall was normal, but there was a range of values $(0 \cdot 7-2 \cdot 1)$ with 29 being $>1.3: 1$ and $11>1.5: 1$ (Fig. 2).

\section{EX-ATHLETES}

The ex-athletes were considered as one group because all but five had competed in endurance events. There was no echocardiographic evidence of left ventricular hypertrophy or dilatation.

\section{ENDURANCE $V S$ STRENGTH ATHLETES}

Table 2 shows the subdivision of the total group into those who competed predominantly in endurance (104) or strength (34) events (excluding wrestlers and judo). Posterior wall and septal thickness, diastolic dimension, and left ventricular mass were significantly increased in the strength athletes $(p<0.05)$; however, after these measurements had been divided by the body surface area the differences were no longer apparent. In particular the $T: R$ ratios 
Table 1 Comparison of left ventricular measurements in athletes, ex-athletes, and non-athletes (normal subjects). Figures are mean $(S D)$

\begin{tabular}{|c|c|c|c|}
\hline Left ventricular measurements & Athletes & Ex-athletes & Non-athletes \\
\hline $\begin{array}{l}\text { No of subjects } \\
\text { Posterior wall }(\mathrm{cm}) \\
\text { Posterior wall }\left(\mathrm{cm} / \mathrm{m}^{2}\right) \\
\text { Septum }(\mathrm{cm}) \\
\text { Septum }\left(\mathrm{cm} / \mathrm{m}^{2}\right) \\
\text { Diastolic dimension }(\mathrm{cm}) \\
\text { Diastolic dimension }\left(\mathrm{cm} / \mathrm{m}^{2}\right) \\
\text { Left ventricular mass }(\mathrm{g}) \\
\text { Left ventricular mass }\left(\mathrm{g} / \mathrm{m}^{2}\right) \\
\text { T:R ratio } \\
\text { Septum : posterior wall ratio }\end{array}$ & $\begin{array}{l}154 \\
1.0(0.2)^{\star \star} \\
0.54(0.1)^{\star \star} \\
1.2(0.2)^{\star \star} \\
0.62(0.1)^{\star \star} \\
5.1(0.5)^{\star \star} \\
2.7(0.4)^{\star} \\
270(93)^{\star \star} \\
143(48)^{\star \star} \\
0.39(0.07)^{\star} \\
1.2(0.2)\end{array}$ & $\begin{array}{l}21 \\
0.8(0.2) \\
0.45(0.1) \\
1.0(0.1) \\
0.55(0.2) \\
4.7(0.3) \\
2.6(0.3) \\
181(60) \\
99(43) \\
0.34(0.04) \\
1.2(0.1)\end{array}$ & $\begin{array}{l}40 \\
0.8(0.1) \\
0.46(0.1) \\
0.9(0.1) \\
0.52(0.1) \\
4.5(0.3) \\
2.55(0.2) \\
155(43) \\
89(29) \\
0.36(0.03) \\
1.1(0.1)\end{array}$ \\
\hline
\end{tabular}

Differences between athletes and non-athletes: ${ }^{\star} \mathrm{p}<0.01,{ }^{\star \star} \mathrm{p}<0.001$; differences between ex-athletes and non-athletes: NS.

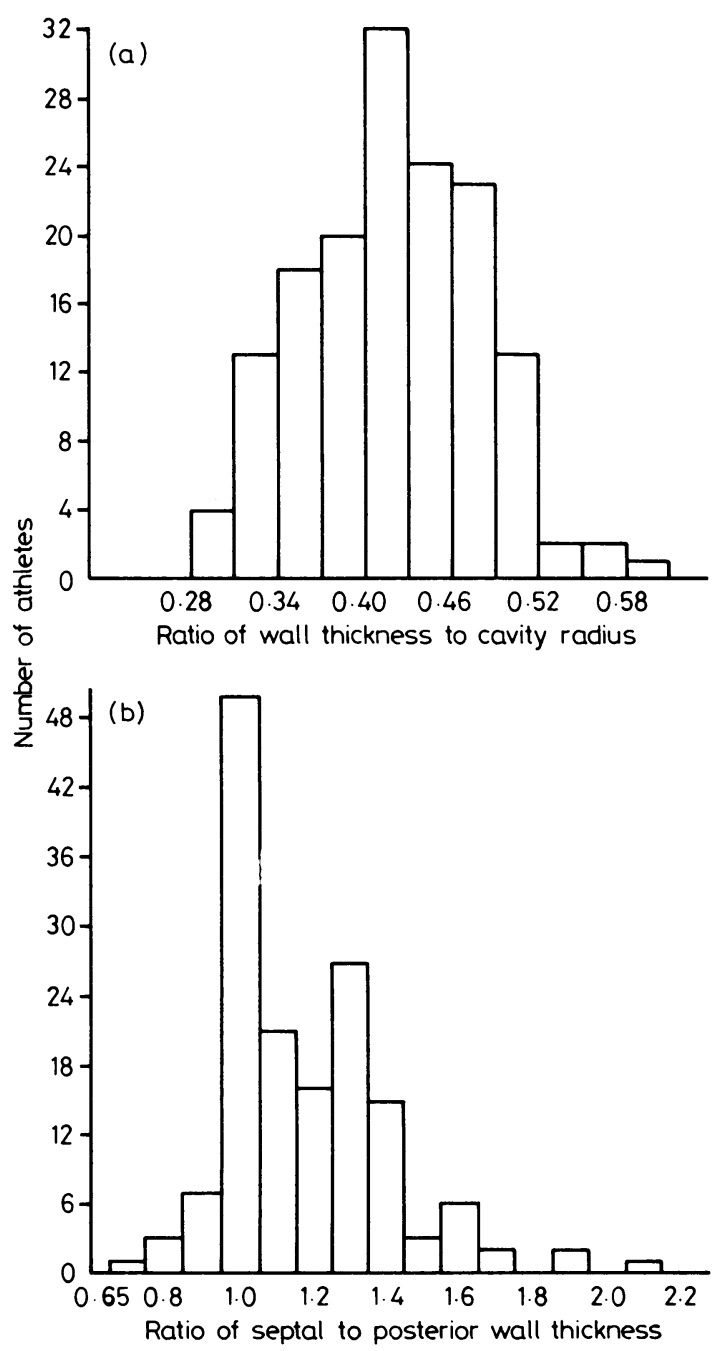

Fig. 2 (a) Ratio of posterior wall thickness to cavity radius; (b) ratio of posterior wall to septal thickness. were similar. The group of strength athletes in this study were intentionally selected to contain some relatively small individuals (light and middle weight weight lifters), and the body surface area of this group was similar to that of the endurance group (1.93 and $1.85 \mathrm{~m}^{2}$ respectively). If only the 12 strength athletes with a body surface area $>2.2 \mathrm{~m}^{2}$ were considered their resting heart rate was similar to that of the nonathletes (69 (9) vs 72 (10) beats/min) as were the measurements of cavity dimension when divided by the body surface area (posterior wall $0.47(0 \cdot 1)$, septum $0.55(0.1) \mathrm{cm}$, diastolic dimension $2.6(0.2) \mathrm{cm}$, and $\mathrm{T}: \mathrm{R}$ ratio $0.37(0.05)$ ), and left ventricular mass was only modestly increased (128 (36) compared with the non-athletes, $\left(89(29) \mathrm{g} / \mathrm{m}^{2}, \mathrm{p}<0.05\right)$.

\section{WRESTLERS}

There were 16 sportsmen who participated in wrestling or judo and they had a similar body surface area to the endurance athletes $\left(1.79 \mathrm{~m}^{2}\right)$. Compared with the non-athletes they had a significant increase $(\mathrm{p}<0.01)$ in the posterior wall and septal thickness and diastolic dimension $(0.53(0.1), 0.6(0.1)$, and $2.7(0.4) \mathrm{cm}$ respectively, all values divided by the body surface area).

Table 2 Comparison of left ventricular hypertrophy in endurance and strength athletes. Figures are mean (SD)

\begin{tabular}{lll}
\hline $\begin{array}{l}\text { Left ventricular } \\
\text { measurements }\end{array}$ & Endurance & Strength \\
\hline No of subjects & 104 & \\
Posterior wall (cm) & $0.97(0.2)$ & $1.05(0.1)^{\star}$ \\
Posterior wall $\left(\mathrm{cm} / \mathrm{m}^{2}\right)$ & $0.53(0.1)$ & $0.54(0.12)$ \\
Septum $(\mathrm{cm})$ & $1 \cdot 1(0.2)$ & $1.25(0.2)^{\star}$ \\
Septum (cm/m $\left.{ }^{2}\right)$ & $0.6(0.1)$ & $0.64(0.1)$ \\
Diastolic dimension $(\mathrm{cm})$ & $5.0(0.5)$ & $5.4(0.5)^{\star}$ \\
Diastolic dimension $\left(\mathrm{cm} / \mathrm{m}^{2}\right)$ & $2.7(0.3)$ & $2.8(0.4)$ \\
Left ventricular mass $(\mathrm{g})$ & $256(87)$ & $319(99)^{\star \star}$ \\
Left ventricular mass $\left(\mathrm{g} / \mathrm{m}^{2}\right)$ & $142(43)$ & $159(60)$ \\
T:R ratio & $0.4(0.07)$ & $0.39(0.05)$ \\
Septum : posterior wall ratio & $1.2(0.2)$ & $1.2(0.2)$ \\
\hline
\end{tabular}

Differences between groups: ${ }^{\star} \mathrm{p}<0.05,{ }^{\star \star} \mathrm{p}<0.001$. 
Table 3 Effect of the standard of competition on left ventricular hypertrophy. Figures are mean (SD)

\begin{tabular}{|c|c|c|c|}
\hline Left ventricular measurements & National & University & Non-competitive \\
\hline $\begin{array}{l}\text { No of subjects } \\
\text { Posterior wall }(\mathrm{cm}) \\
\text { Posterior wall }\left(\mathrm{cm} / \mathrm{m}^{2}\right) \\
\text { Septum }(\mathrm{cm}) \\
\text { Septum }\left(\mathrm{cm} / \mathrm{m}^{2}\right) \\
\text { Diastolic dimension }(\mathrm{cm}) \\
\text { Diastolic dimension }\left(\mathrm{cm} / \mathrm{m}^{2}\right) \\
\text { Left ventricular mass }(\mathrm{g}) \\
\text { Left ventricular mass }\left(\mathbf{g} / \mathrm{m}^{2}\right) \\
\text { T:R ratio } \\
\text { Septum : posterior wall ratio }\end{array}$ & $\begin{array}{l}59 \\
1.1(0.1) \\
0.58(0.1) \\
1.3(0.2) \\
0.71(0.1) \\
5.4(0.8) \\
2.8(0.3) \\
310(94) \\
163(50) \\
0.42(0.07) \\
1.2(0.2)\end{array}$ & $\begin{array}{l}66 \\
0.95(0.2)^{\star \star} \\
0.52(0.1)^{\star} \\
1.1(0.2)^{\star \star} \\
0.6(0.1) \\
5.1(0.5) \\
2.7(0.3) \\
258(84)^{\star} \\
138(44)^{\star} \\
0.38(0.06)^{\star \star} \\
1.2(0.3)\end{array}$ & $\begin{array}{l}29 \\
0.85(0.1)^{\star \star} \\
0.48(0.1)^{\star \star} \\
1.0(0.2)^{\star \star} \\
0.56(0.1)^{\star \star} \\
4.9(0.3)^{\star} \\
2.7(0.3) \\
207(64)^{\star \star} \\
114(31)^{\star \star} \\
0.35(0.03)^{\star \star} \\
1.1(0.1)\end{array}$ \\
\hline
\end{tabular}

Difference between national and other standard athletes: ${ }^{\star} \mathrm{p}<0.01,{ }^{\star} \mathrm{p}<0.001$.

\section{EFFECT OF THE STANDARD OF COMPETITION ON}

\section{LEFT VENTRICULAR HYPERTROPHY}

To consider the effect of the standard of exercise, national, university, and non-competitive sportsmen were compared. This division is necessarily arbitrary since some national standard athletes may spend less time per week exercising than those enthusiasts who have less sporting ability. On average, however, the national standard athletes spent more time per week exercising than the university or non-competitive groups ( 9.1 vs 6.3 and 4.2 hours, NS). In addition, a large proportion of the non-competitive group performed predominantly ball sports. Although diastolic dimension was not significantly enlarged, there was significant thickening of the posterior wall and septum with increased left ventricular mass and $T: R$ ratio in the national standard athletes compared with the others (Table 3).

\section{Discussion}

Earlier this century, with the advent of modern athletics and training methods, it became apparent that highly trained individuals could develop bradycardias, cardiac enlargement, murmurs, and added heart sounds. ${ }^{20}$ The electrocardiogram and chest radiograph showed abnormalities similar to those found in heart disease, and these cardiac findings were thought to be due to the effects of exercise and not disease. ${ }^{21}$ The present study has shown that a wide spectrum of left ventricular hypertrophy may be found in athletes which is predominantly related to the amount but not the type of exercise.

There are methodological problems in the study of the heart in athletes. There is little collaborative evidence from necropsy studies because the very few deaths that occur are due to other forms of heart disease (coronary artery disease and hypertrophic cardiomyopathy).2223 Although animal experiments confirm that exercise will induce reversible changes in cardiac structure, there is a wide species variation in its extent so that it is doubtful whether animal models reflect human experience. ${ }^{24} 25$ There are also problems with classifying the level of athletic training. A dedicated swimmer or runner can obtain a high level of training in three hours per week (six sessions of 30 minutes each), but this will not occur with a similar duration of weight lifting or shot putting.

Echocardiography allows repeated non-invasive investigation of athletes and has led to advances in the study of physiological left ventricular hypertrophy. Previous echocardiographic studies have shown left ventricular cavity enlargement in athletes. ${ }^{1-18}$ The increased end diastolic cavity size (and stroke volume) explains the mechanism by which athletes sustain a high cardiac output during exercise. Since peak heart rate is principally determined by age not training, and ejection fraction remains constant, cardiac size is therefore the determinant of the increased cardiac output in athletes. Echocardiographic studies show that diastolic cavity dimension may increase from $3 \%$ greater than normal in runners ${ }^{6}$ to $19 \%$ in runners ${ }^{7}$ and cyclists. ${ }^{11}$ The present study shows on average an $11 \%$ increase in diastolic dimension, which reduces to $6 \%$ when divided by the body surface area. During periods of training an increase in diastolic dimension of $4-8 \%$ has been found. 51316 Although this appears to be a small increase, assuming that ejection fraction remains constant and diastolic dimension increases by only $6 \%$, stroke volume will increase by $18 \%$. It must, however, be considered that differences of $0.2-0.3 \mathrm{~cm}$ in cavity size are close to the reproducibility of the method and that the cavity enlargement may merely be due to the reduced heart rate.

Disproportionate or asymmetrical septal hypertrophy was initially thought to be specific for hypertrophic cardiomyopathy, ${ }^{26}$ but it may be found in other forms of left ventricular hypertrophy. ${ }^{27}$ Seven per cent of our athletes had a septum to posterior wall ratio $>1.5: 1$, and in a further $21 \%$ it was greater than 1.3:1 (Fig. 2b). It is of interest that those with a left ventricular mass $>2 S D$ from normal had a proportionally thicker septum than those with less hypertrophy. This would provide further evidence that septal 
thickening is a normal manifestation of secondary left ventricular hypertrophy of whatever cause.

Echocardiographic studies in athletes have shown that training may result in an increased left ventricular mass with increased wall thickness and cavity size, but a series of conflicting views have arisen..$^{1-17}$ Morganroth and coworkers ${ }^{7}$ suggested that isometric exercise will result in wall thickening and isotonic exercise in cavity dilatation. The former would, however, appear to result in concentric hypertrophy (with an increased $T: R$ ratio as found in pressure overload), and the latter would increase wall stress, both of which would appear to be non-physiological. 142829 This argument is based on two groups of athletes, one of which contains four world champion shot putters with enormous body mass and an increased $T: R$ ratio, who after the dimensions had been divided by the body surface area (the mean quoted value) had normal wall thickness and a small left ventricular cavity. To maintain the huge body mass required for top class participation in shot putting very little endurance training is performed, and these four subjects probably had a very low level of "cardiovascular fitness." The other group of isometric athletes described were wrestlers (who did show significant wall thickening); they had normal body mass and a resting bradycardia and presumably must have been endurance as well as isometrically trained. We studied a similar group of subjects who did not have inappropriate hypertrophy. Comparison of the percentage increase in the $T: R$ ratio for sportsmen compared with normal subjects shows that most are within $15 \%$ of the normal quoted value and only the studies of Morganroth, ${ }^{7}$ Sugishita, ${ }^{18}$ and Ikäheimo $^{3}$ found values greater than this; the latter study described long distance runners and not strength athletes. The data in this study show that the $T: R$ ratio is a single continuously distributed variable and not bimodally distributed as would have been expected if concentric hypertrophy occurred in strength athletes. In addition, separate analysis of athletes with a huge body mass also does not show an increased $T: R$ ratio. Therefore, there would appear to be little to suggest that exercise results in inappropriate hypertrophy.

The physiological adaptations of the circulatory system to endurance and strength events are necessarily different, but it is unknown whether they result in a detectable structural difference. Extrapolation from disease suggests that an increase in the $T: R$ ratio occurs in response to pressure overload. $2829 \mathrm{In}$ contrast to the initial hypothesis that the $T: R$ ratio increases in strength athletes, the present and other studies show that such an increase occurs in response to many different forms of exercise intense enough to cause left ventricular hypertrophy. 246101116 Anaerobic energy release can be maintained only for a very short period of time. Therefore in strength events and other sports where a substantial rise in systolic blood pressure occurs at peak exercise the cardiac stimulus is pressure overload, which should theoretically result in concentric left ventricular hypertrophy. Nevertheless, the very transient duration of this load may not affect the heart as it would be difficult to understand why a moderately raised left ventricular systolic pressure for a very short period of time per day would increase the $T: R$ ratio, whereas prolonged pressure overload in aortic stenosis or hypertension may fail to do so. In conclusion, the study of a large group of athletes has shown that left ventricular hypertrophy may frequently be detected by echocardiography and appears to be related to the duration of the activity rather than to its type.

I thank the staff and students of the University of Birmingham Physical Education Department for their invaluable help and especially Bob Smith, Craig Sharp, and Bill Tuxworth. In addition, I thank Dr Derek Gibson for the use of echocardiographic equipment and critical review of the manuscript.

\section{References}

1 DeMaria AN, Neumann A, Lee G, Fowler W, Mason DT. Alterations in ventricular mass and performance induced by exercise training in man evaluated by echocardiography. Circulation 1978; 57: 237-44.

2 Ehsani AA, Hagberg JM, Hickson RC. Rapid changes in left ventricular dimensions and mass in response to physical conditioning and deconditioning. Am $\mathcal{F}$ Cardiol 1978; 42: 52-6.

3 Ikäheimo MJ, Palatsi IJ, Takkunen JT. Noninvasive evaluation of the athletic heart: sprinters versus endurance runners. Am $\mathcal{F}$ Cardiol 1979; 44: 24-30.

4 Cohen JL, Gupta PK, Lichstein E, Chadda KD. The heart of a dancer: noninvasive cardiac evaluation of professional ballet dancers. Am $\mathcal{F}$ Cardiol 1980; 45: 959-65.

5 Wieling W, Borghols EAM, Hollander AP, Danner SA, Dunning AJ. Echocardiographic dimensions and maximum oxygen uptake in oarsmen during training. $\mathrm{Br}$ Heart F 1981; 46: 190-5.

6 Gilbert CA, Nutter DO, Felner JM, Perkins JV, Heymsfield SB, Schlant RC. Echocardiographic study of cardiac dimensions and function in the endurancetrained athlete. Am $\mathcal{F}$ Cardiol 1977; 40: 528-33.

7 Morganroth J, Maron BJ, Henry WL, Epstein SE. Comparative left ventricular dimensions in trained athletes. Ann Intern Med 1975; 82: 521-4.

8 Longhurst JC, Kelly AR, Gonyea WJ, Mitchell JH. Echocardiographic left ventricular masses in distance runners and weight lifters. I Appl Physiol 1980; 48: $154-62$.

9 Adams TD, Yanowitz FG, Fisher AG, Ridges JD, Lovell K, Pryor TA. Noninvasive evaluation of exercise training in college-age men. Circulation 1981; 64: 958-65.

10 Bekaert I, Pannier JL, Van De Weghe C, van Durme JP, 
Clements DL, Pannier R. Non-invasive evaluation of cardiac function in professional cyclists. $\mathrm{Br}$ Heart $\mathcal{F}$ 1981; 45: 213-8.

11 Nishimura T, Yamada Y, Kawai C. Echocardiographic evaluation of long-term effects of exercise on left ventricular hypertrophy and function in professional bicyclists. Circulation 1980; 61: 832-40.

12 Hickson RC, Holloszy JO. Time course of the regression of cardiac hypertrophy following cessation of endurance exercise training [Abstract]. Med Sci Sports 1977; 9: 73.

13 Fagard R, Aubert A, Lysens R, Staessen J, Vanhees L, Amery A. Noninvasive assessment of seasonal variations in the cardiac structure and function in cyclists. Circulation 1983; 67: 896-901.

14 Rost R. The athlete's heart. Eur Heart $\mathcal{F}$ 1982; 3 (suppl A): $193-8$.

15 Roeske WR, O'Rourke RA, Klein A, Leopold G, Karliner JS. Noninvasive evaluation of ventricular hyertrophy in professional athletes. Circulation 1976; 53: 28692.

16 Shapiro LM, Smith RG. Effect of training on left ventricular structure and function: an echocardiographic study. Br Heart $\mathcal{F}$ 1983; 50: 534-9.

17 Stein RA, Michielli D, Diamond J, Horwitz B, Krasnow $\mathrm{N}$. The cardiac response to exercise training: echocardiographic analysis at rest and during exercise. Am $\mathcal{F}$ Cardiol 1980; 46: 219-25.

18 Sugishita Y, Koseki S, Matsuda M, Yamaguchi T, Ito I. Myocardial mechanics of athletic hearts in comparison with diseased hearts. Am Heart $\mathcal{F}$ 1983; 105: 273-80.
19 Shapiro LM, McKenna WJ. Distribution of left ventricular hypertrophy in hypertrophic cardiomyopathy: a two-dimensional echocardiographic study. $\mathcal{F}$ Am Coll Cardiol 1983; 2: 437-44.

20 Henschen SE. Skilauf und Skiwettlauf. Eine medizinische Sportstudie. Mitteilungen aus der medizinischen Klinik zu Upsala 1899; 2: 15-36.

21 Roskamm H, Wink K, Reindell H. Die Arbeitsweise des Herzens bei chronischer physiologischer Mehrbelastung (Sportherz). Medizinische Klinik 1972; 67: 1097-103.

22 Maron BJ, Epstein SE, Roberts WC. Hypertrophic cardiomyopathy: a common cause of death in the young competitive athlete. Eur Heart $\mathcal{F}$ 1983; 4 (suppl F): 13544.

23 Anonymous. Marathon runners and ischaemic heart disease [Editorial]. Lancet 1978; ii: 718-9.

24 Ford LE. Heart size. Circ Res 1976; 39: 297-303.

25 Wikman-Coffelt J, Parmley WW, Mason DT. The cardiac hypertrophy process. Circ Res 1979; 45: 697-707.

26 Henry WL, Clark CE, Epstein SE. Asymmetric septal hypertrophy: echocardiographic identification of the pathognomonic anatomic abnormality of IHSS. Circulation 1973; 47: 225-33.

27 Gibson DG, Traill TA, Hall RJC, Brown DJ. Echocardiographic features of secondary left ventricular hypertrophy. Br Heart f 1979; 41: 54-9.

28 Gaasch WH. Left ventricular radius to wall thickness ratio. Am F Cardiol 1979; 43: 1189-94.

29 Grossman W. Cardiac hypertrophy: useful adaptation or pathologic process? Am $\mathcal{F}$ Med 1980; 69: 576-84. 